\title{
Sutam y komonil: defensa territorial y existencia colectiva de comunidades poqomchi'-q'eqchi' en Baja Verapaz, Guatemala*
}

\author{
ROMINA MARTÍNEZ VELARDE, FERNANDO LIMÓN AGUIRRE, \\ CARLA BEATRIZ ZAMORA LOMELÍ Y MÁXIMO ABRAHÁN BÁ TIUL
}

ROMINA MARTíNEZ VELARDE El Colegio de la Frontera Sur, San Cristóbal

de las Casas, Chiapas, México romina.martinez.velarde@gmail.com

FERNANDO LIMÓN AGUIRRE El Colegio de la Frontera Sur, San Cristóbal de las Casas, Chiapas, México flimon@ecosur.mx

CARla BeATRIZ ZAMORA LOMELÍ El Colegio de la Frontera Sur, San Cristóbal de las Casas, Chiapas, México czamora@ecosur.mx

MÁXIMO ABRAHÁN BÁ TIUL Investigador independiente. chiwax2030@yahoo.com
En este artículo se ofrece una aproximación analítica a la dimensión cultural de la defensa territorial de comunidades poqomchi'-q'eqchi' en Baja Verapaz, Guatemala, con base en una investigación cualitativa realizada desde la perspectiva de la investigación-acción participante. Se analizan dos nociones estructurales: sutam -territorio-y komonil -dimensión y organización colectiva de la existencia-, entendidas como parte de sus conocimientos culturales, su memoria y esperanzas colectivas en relación con el territorio y la política. Se trata de la defensa de los bienes necesarios para reproducir la vida en comunidad, así como sus modos particulares de ver y organizar la vida frente a experiencias de desplazamiento y amenazas de proyectos hidroeléctricos.

PALABRAS CLAVE: territorio, dimensión cultural, conocimientos culturales, Sierra de las Minas, investigación-acción participante

\section{Sutam and komonil: Territorial Defense and Collective Existence} of Poqomchi'-Q'eqchi' Communities in Baja Verapaz, Guatemala

This article provides an analytical approximation of the cultural dimension regarding territorial defense of Poqomchi'-q'eqchi' communities located in Baja Verapaz, Guatemala, based in a qualitative investigation with a participatory action research perspective. Two main aspects are analysed: sutam -territory - and komonil -dimension and collective organization of existence-, both understood as part of their cultural knowledge, their collective memories and hopes regarding territory and politics. This article is about the collective defense of the necessary goods to reproduce communal life, and their particular point of view on how to organize life facing displacement experiences and threats of hydroelectric projects.

KEYWORDS: territory, cultural dimension, cultural knowledge, Sierra de las Minas, participatory action research 


\section{Introducción}

rente a un contexto en el que predomina un modelo económico de sobreexplotación de la naturaleza y despojo de bienes naturales de comunidades campesinas y pueblos indígenas, se verifican procesos organizativos de defensa territorial. Esta defensa dista mucho de ser sólo de los bienes materiales y la posesión de los recursos para reproducir la vida, ya que también defiende los modos particulares de ver y organizar la vida, así como la dignidad colectiva.

En la Sierra de las Minas, localizada en el municipio de Purulhá, departamento de Baja Verapaz, Guatemala, las comunidades indígenas mayas poqomchi'-q'eqchi ${ }^{1}$ enfrentan ahora una amenaza más a su vida y sus territorios: la construcción de al menos dos proyectos hidroeléctricos y la actual operación de otras cuatro hidroeléctricas en Baja Verapaz. Estos proyectos, además, se dan en el marco de un plan de conservación ambiental conflictivo y polémico.

En el presente artículo se ofrece una aproximación analítica a la dimensión cultural de la defensa territorial de estas comunidades y se abordan dos nociones estructurales: el sutam — territorio- y el komonil — la dimensión y organización colectiva de la existencia-. Éstos y otros elementos se articulan y analizan desde el

* $\quad$ Agradecemos a la comunidad Renacimiento Vega Larga 1 y las comunidades en resistencia en la Sierra de las Minas su confianza y disposición para compartir sus experiencias. Agradecemos también la beca otorgada por el Consejo Nacional de Ciencia y Tecnología de México a Romina Martínez Velarde y la beca mixta que hizo posible su estancia académica en la Universidad Rafael Landívar, Guatemala. Gracias al Instituto de Agricultura, Recursos Naturales y Ambiente de la Universidad Rafael Landívar, y en particular, a Raúl Mass, Mario López y Juan Blanco.

1 Diversas fuentes determinan que los nombres de pueblos, tribus, etnias e idiomas, así como los gentilicios, deben escribirse con minúsculas en español (URL, 1992; RAE, 2005; Bezos, 2012). Además, se ha decidido escribir poqomchi', en lugar de pocomchi', pokomchi', poq'omchi', y q'eqchi', en lugar de kekchi' o q'ekchi', debido a que ésta es la ortografía utilizada por la Academia de Lenguas Mayas de Guatemala (ALMG, 2001). 
marco de los conocimientos culturales, la memoria y esperanzas colectivas, la territorialización y la política (Limón, 2008; 2009; 2010).

El sustento de nuestro análisis, además del conocimiento que de la región y el proceso organizativo tiene desde hace más de una década uno de los coautores de este texto, ha sido la realización de una investigación participante en las comunidades de Renacimiento Vega Larga 1, Ribacó y La Hamaca, con una estancia de seis meses en la primera de ellas. Esta comunidad fue fundada en 1998 como resultado del despojo y expulsión de sus tierras suscitados en el marco de la implementación de políticas neoliberales de conservación ambiental en Guatemala, por medio de la declaración del área natural protegida Reserva Biósfera Sierra de las Minas, de 242642 ha, por decreto número 49-90 del Congreso de la República, en 1990 (López, 2016).

Al encontrarse Vega Larga dentro de la zona núcleo, sus habitantes fueron obligados a desplazarse en condiciones denigrantes, lo que constituye un agravio que se mantiene a flor de piel. A más de 20 años, la comunidad de Renacimiento Vega Larga 1 continúa en resistencia, junto con otras 30 comunidades, en la defensa de sus territorios y sus respectivos modos de vida, frente a renovadas amenazas de despojo.

\section{Antecedentes}

Esta investigación se enmarca en el campo de la ecología política latinoamericana, en la que Joan Martínez-Alier (2015) invita a analizar los conflictos socioambientales y las luchas en defensa del territorio sin perder de vista las relaciones de poder que inciden en estos conflictos. En este sentido, partimos de señalar que las comunidades poqomchi'-q'eqchi' de la Sierra de las Minas han experimentado varios ciclos de despojo que se mantienen en su memoria y constituyen un continuum: la invasión española, la herida colonial, las injusticias del sistema de fincas poscolonial y la violencia vivida durante el Conflicto Armado Interno en Guatemala en la segunda mitad del siglo pasado. Sin embargo, durante este periodo se han documentado luchas y resistencias protagonizadas por las comunidades, que despliegan estrategias para su supervivencia y para la defensa de sus territorios (Martínez, 2006; López, 2016), entre las cuales es posible identificar procesos históricos de desterritorialización-reterritorialización y de multiterritorialidad, o capacidad de articular simultáneamente múltiples territorios, que concuerdan con dicha perspectiva (Haesbaert, 2013).

Dos detonantes contemporáneos del despojo, que afectan a las comunidades poqomchi'-q'eqchi' de la zona de estudio, son las declaratorias de áreas naturales protegidas y los proyectos hidroeléctricos. Las primeras se ejecutan bajo la concepción de grupos y entidades conservacionistas que comprenden al ser humano como un ente antagónico o separado de la naturaleza. En cuanto a los proyectos hidroeléctricos, a partir de 2003 se presentó en Guatemala un desarrollo explosivo de este sector, con particular beneplácito de los sectores agroindustrial y cafetalero.

En el caso del territorio de la Sierra de las Minas, destacan otras dos actividades consideradas extractivas: ${ }^{2}$ la minería y la industria maderera, ambas identificadas y señaladas por la población local. Debido a la amenaza que todas estas actividades representan, surge el proceso actual de resistencia intercomunitaria en defensa de sus territorios.

El esfuerzo colectivo, organizativo y defensivo de las comunidades de la Sierra de las Minas, que a su vez es de resistencia e insubordinación, puede ser

2 De acuerdo con Raphael Hoetmer, el extractivismo "no sólo consiste en la extracción de grandes cantidades de bienes comunes para la exportación [...] sino también en la configuración de un sistema político, económico, jurídico e imaginario cultural e identitario que permite su desarrollo" (2017: 5). 


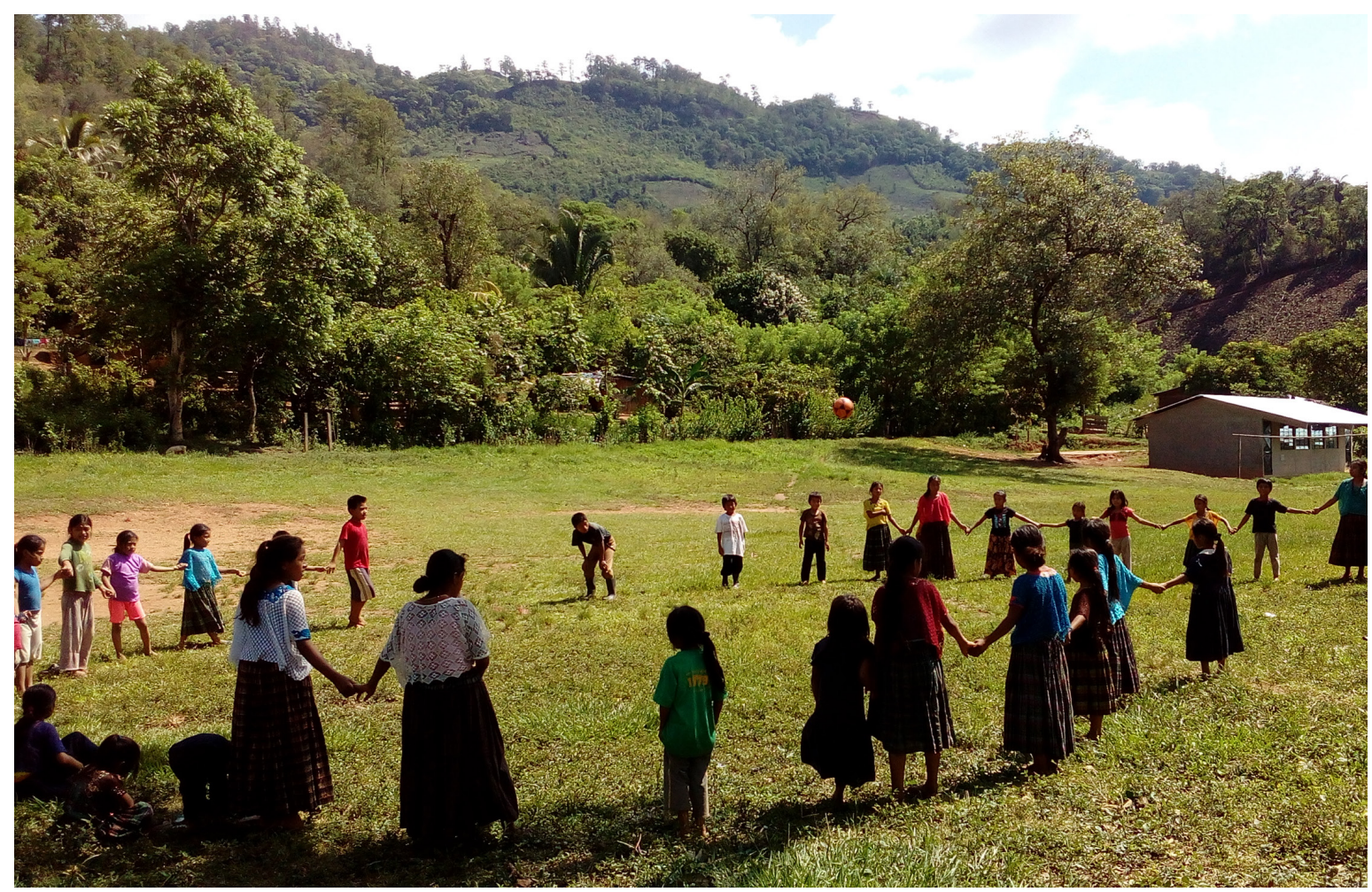

Romina MARTinez VeLARDE - Niñas y niños juegan en el campo de futbol. Renacimiento Vega Larga 1.

considerado, como plantea Arturo Escobar (2014: 50), "materialidad históricamente sedimentada [...] de las formas culturales de larga data".

\section{Encuadre teórico-metodológico}

De acuerdo con Carlos Walter Porto-Gonçalves (2002), el interés por el territorio surge a partir de las reivindicaciones de los pueblos indígenas, campesinos y afrodescendientes de países latinoamericanos como Bolivia, Ecuador, Perú, Colombia y Brasil, a finales de la década de 1980 y principios de la de 1990. Estos pueblos y grupos sociales "introducen por primera vez el tema del territorio en los debates teórico-políticos, imponiendo así una gran resignificación al debate sobre tierras y territorio en el continente" (Escobar, 2015: 95).
Existen distintas aproximaciones a la cuestión territorial (Giménez, 2005; Hadad y Gómez, 2007), pero en esta investigación se apuesta por una mirada fenoménico-política e integral del territorio, al que concebimos como "un ámbito de interacciones y, sobre todo, un espacio específico de memorias concretas y vividas a partir de las que se establecen [...] relaciones, se constituye el nosotros como comunidad y se construye la esperanza” (Limón, 2008: 90).

Bajo este entendimiento, de acuerdo con la perspectiva de la ecología política, en el territorio se constituye lo comunitario y se construyen aspiraciones, anhelos y reivindicaciones. Escobar (1999: 18) resalta el vínculo territorio-comunidad al afirmar que "el territorio es la encarnación del proyecto de vida de una comunidad".

Otro referente teórico es Rogério Haesbaert (2013), quien profundiza en el tema por medio de 
las nociones de territorialidad, multiterritorialidad, desterritorialización-reterritorialización; enfatiza el carácter relacional del territorio, y hace una apuesta por superar las dicotomías espacio/tiempo, móvil/ inmóvil, funcional/simbólico, presentes con frecuencia en las discusiones sobre la definición del territorio. Se trata de una dialéctica múltiple que enmarca a la experiencia, y al mismo tiempo que interpela a la cultura, la compele a posicionarse al renovar su ofrecimiento de sentido de la existencia.

El mismo Haesbaert afirma que "el territorio está vinculado siempre con el poder y con el control de procesos sociales mediante el control del espacio" y ello provoca numerosos conflictos y disputas territoriales en las que "se dibujan nuevas-viejas estrategias de control territorial” (2013:13).

Los procesos de resistencia y lucha relativos a la disputa por los bienes comunes naturales ${ }^{3}$ han sido caracterizados de distintas formas desde el campo de la ecología política latinoamericana. En esta investigación se retoma el concepto de luchas en defensa del territorio que articula y contiene la dimensión cultural, más allá de la posesión y usufructo de la tierra, sin omitirles.

Si bien la categoría de defensa del territorio es relativamente reciente, alude a experiencias comunitarias antiguas de organización y lucha. En nuestro caso de estudio, ésta es la noción enarbolada por las comunidades involucradas, en las que se remarca que la posesión de sus territorios no puede desligarse de la lucha por su defensa, lo que nos ofrece una perspectiva de análisis.

Respecto de la dimensión cultural, Bolívar Echeverría (2010: 17) invita a buscar, reconocer y describir sus "efectos en la realidad social y en el acontecer histórico", pues además de ser algo que se construye, destruye y restituye permanentemente al verificarse en la cotidianidad, en ella "la existencia humana [...] se afirma como tal” (2010: 20). Nuestro planteamiento es que la dimensión cultural de la vida social en las comunidades estudiadas, no sólo es uno de los factores que ha inducido — antes y ahora - su proceso de defensa territorial, sino su principal eje vertebrador y de perseverancia, pues le confiere sentido, le suministra recursos memorísticos, ajusta su modo de vida y remite a lo no negociable: su comprensión y asunción como defensa de la vida.

Finalmente, se incorpora la propuesta de los conocimientos culturales —que pautan la existencia de los pueblos y le dan sentido de vida y orientación ética a sus acciones (Limón, 2008; 2009; 2010) — pues constituyen un marco epistemológico, teórico y metodológico que aporta recursos para la comprensión e interpretación del modo de vida de los pueblos, con un posicionamiento que hace eco de sus luchas y anhelos en sus espacios territoriales. Su potencial militante, al suscribir la ontología de la esperanza, del "aún no", favorece la articulación de los elementos sobresalientes en la constelación que permite su existencia, en un análisis crítico, contextual e histórico, que pone de relieve la dimensión cultural de los procesos de defensa del territorio.

En términos metodológicos, este estudio se inscribe en la tradición comprensiva —investigación cualitativa - y hace una apuesta por una investigación de índole comprensivo-explicativa que remarca la empatía, lo vivencial y lo flexible a favor del diálogo. Asimismo, se ubica en la perspectiva de la investigación-acción participante, con énfasis en el carácter participante, ya que además de incorporar métodos horizontales y participativos como una de sus estrategias, suscribe la intención de sumarse y aportar al proceso y las causas manifiestas que le anteceden y la trascienden.

3

Preferimos utilizar el término "bienes comunes naturales" en lugar de "recursos naturales". 
Las técnicas que se utilizaron a lo largo de la investigación, que implicó una estancia de febrero a agosto de 2017 en la comunidad Renacimiento Vega Larga 1, fueron principalmente de tipo etnográfico, como la observación participante, con anotaciones en diario y libreta de campo. La observación y el registro de las dinámicas de las personas en su cotidianidad se llevaron a cabo mediante el involucramiento en sus actividades, para favorecer una mejor comprensión de sus procesos, motivos, causas, reflexiones y quehaceres. Se realizaron entrevistas etnográficas — no estructuradas ni estandarizadasen las interacciones cotidianas y de manera espontánea, lo que dio pauta para que la gente hablara "acerca de lo que ellos conocen" (Spradley, citado en Vela-Peón, 2001: 6).

Se aplicó una entrevista estructurada a 16 comunitarias y comunitarios ${ }^{4}$ de la Sierra de las Minas, y una más a una colaboradora de la Fundación Defensores de la Naturaleza, organización que tiene la administración del área natural protegida de la Sierra de las Minas. Otra técnica fundamental fue la realización de talleres participativos, concebidos como espacios de trabajo, discusión grupal y construcción colectiva de conocimiento. De manera simultánea, se llevó a cabo una revisión bibliográfica, documental y de materiales elaborados por la comunidad y por la organización intercomunitaria.

En la estancia de campo, la barrera lingüística debía ser superada. Esto se procuró por medio de relaciones de cercanía y amistad, y formas de comunicación no verbales durante la convivencia y el trabajo cotidianos, así como mediante el apoyo de jóvenes con disposición y habilidades para interpretar y traducir. Los resultados que se exponen en este artículo se presentaron y entregaron a la comunidad de Renacimiento Vega Larga 1 en febrero de 2018, por medio de una exposición, con diálogo y entrega de textos, fotografías y mapas, lo que ha permitido la verificación de nuestras interpretaciones.

\section{Resultados}

\section{CONOCIMIENTOS CULTURALES Y DEFENSA DEL TERRITORIO}

En este caso, el conocimiento cultural se concentra en la cuestión de la resistencia, la negatividad, el ¡no! a lo que atropella, excluye, niega y se impone; el ¡no! a lo que atenta contra la vida y la dignidad, es decir, contra aquello que amenaza el particular modo de vida de las comunidades poqomchi'-q'eqchi' en la Sierra de las Minas y su cosmovisión.

A estas comunidades se les ha despojado de sus territorios y asediado desde hace por lo menos 500 años. En la actualidad se impone un modelo de desarrollo extractivista que se materializa en proyectos hidroeléctricos, mineros y de monocultivo; proyectos que rechazan y frente a los cuales están renovando sus formas organizativas de lucha ancestrales.

Al mismo tiempo, aunque de una forma quizá más sutil pero no menos violenta, se pretende imponer la lógica de la modernidad en modos de consumo, formas de gobierno y sistemas médico y educativo, entre otros. Precisamente frente a estas pretensiones, en su defensa territorial las comunidades de estudio en la Sierra de las Minas vigorizan sus conocimientos culturales y así sustentan su resistencia a esta embestida, en un proceso de reterritorialización en términos de Haesbaert (2013).

Este tipo de conocimientos son el correlato dialéctico del modo en el que se vive la vida con sentido en la comunidad, y sustentan, fortalecen y orientan sus procesos de resistencia. A continuación, exponemos algunas de las expresiones que constatan este entendimiento:

\footnotetext{
$4 \quad$ Por acuerdo con la comunidad, y para evitar poner en riesgo a las personas que formaron parte de este trabajo colectivo, se mantiene su anonimato y se utilizan seudónimos para proteger su identidad.
} 
A mí me ayuda para la lucha lo que me enseñó mi papá sobre respetar a las demás personas, a hombres y mujeres. Y me enseñó cómo vivir bien dentro de las comunidades, con la gente. Cómo comportarse, cómo vivir (entrevista con Eduardo Quej, Renacimiento Vega Larga 1, agosto de 2017).

Los abuelos nos enseñaron el respeto y el cuidado. También nos enseñaron nuestro idioma, que nos da fuerza, y la forma de vestir, que ahí es donde se muestra que somos de aquí. Por la gracia se está levantando otra vez lo que es bueno (entrevista con Emiliano Iqui, Washington, junio de 2017).

Estas palabras, más allá de la lógica del discurso, se encuentran dotadas de contenido y práctica, como se atestiguó y documentó al compartir la vida cotidiana con estas personas. "Vivir bien” y "saber cómo comportarse" forma parte de su modo de vida y ello "muestra que somos de aquí", algo que destacan como el sentido de su vida y la dirección de su caminar.

Estas expresiones, que revelan sus particulares formas de comprensión de la vida, el entorno y la naturaleza, se basan en su memoria y su relación con el espacio que habitan como territorio; conllevan, además, una carga de esperanza. Estos conocimientos son medulares para su lucha porque ponen en evidencia y reivindican su particular modo de vida: "luchar por el territorio o por [su] defensa [es] luchar [...] por la no colonización del modo de vida [...]. De balde un pueblo defiende su territorio si no refrenda [...] su modo de vida. De no hacerlo, lo que está defendiendo es un terreno, no un territorio, que es por excelencia el espacio simbólico, dialogal y comunitario" (Limón, 2007: 349).

Esto nos recuerda la siguiente expresión de Lorena Navarro, luego de su estudio sobre las luchas campesinas e indígenas contra la explotación capitalista: "el histórico y profundo vínculo que las comunidades indígenas y campesinas han tejido con el territorio las ha situado en un férreo proceso de resistencia contra todo tipo de proyectos de extracción y despojo de los bienes comunes naturales, principalmente de la tierra" (2013: 77).

Por ello es posible afirmar que en el caso de esta lucha por la defensa territorial, con su intencionalidad económica implícita en la posesión y el usufructo de la tierra, la dimensión cultural de la vida social de las comunidades poqomchi'-q'eqchi' también está incluida. Su identificación, que se constata en lo comunitario y organizativo del proceso, se proclama con fuerza y potencia, como se muestra en la Primera Declaración de Tezulutlán, de 2012, de las comunidades en resistencia en la Sierra de las Minas:

Somos una unidad, aunque seamos de diferentes pueblos, nos identificamos con nuestro conocimiento, nuestra espiritualidad, nuestra cosmovisión [...]. Tenemos que defender el agua, el bosque, los animales, porque somos parte de ella, somos parte de un todo [...]. Estando en comunidad defendemos a nuestra comunidad, nuestras semillas, nuestro territorio y nuestra vida (citado en López, 2016).

Cuando se afirma: "defendemos nuestro conocimiento", se trata de un conocimiento común, compartido, pues ofrece sentido de trascendencia en y por la lucha, al defenderse la vida y el modo particular de vivir. Ello se relaciona con todo el entramado de elementos significativos de su cultura, este conocimiento orienta y da sentido a la acción en la medida en que articula memoria y esperanza (taller sobre anhelos comunitarios con hombres, Renacimiento Vega Larga 1, agosto de 2017). 


\section{SUTAM: EL TERRITORIO PARA LAS COMUNIDADES} POQOMCHI'-Q'EQCHI'

\section{¿Qué es el sutam?}

En las comunidades poqomchi'-q'eqchi' en las que se realizó este trabajo, la gente se refiere al sutam cuando se pregunta y se habla sobre el territorio. ${ }^{5}$ ¿Qué es lo que expresa esta palabra? Al consultarle a uno de los comunitarios cómo se decía "territorio" en poqomchi', afirmó: “sutam chi riij qaye’ aab”, lo que literalmente se entendería como "lo que rodea a la comunidad" o "lo que está atrás de la comunidad" (entrevista con José Luis Caal, Renacimiento Vega Larga 1, agosto de 2017).

En esta definición resaltan dos aspectos: 1) que la noción de territorio incluye la de komoon - la estructura social, política y económica, como veremos más adelante- , que da testimonio de un entramado de relaciones vitales y es de hecho más amplia que la noción de comunidad, concerniente sólo a personas; 2) la referencia a "lo que rodea" o "lo que está atrás", reiterada en entrevistas y en los talleres participativos realizados durante la estancia de campo.

En las entrevistas se nos dijo que sutam es "todo lo que está alrededor de uno” (entrevista con Marcela Ichich, La Hamaca, junio de 2017); "nuestro lugar" (entrevista con Abraham Iqui, La Ceibay Dos Fuentes, junio de 2017, y con José Luis Caal, Renacimiento Vega Larga 1, agosto de 2017); “todo lo que está dentro, cerca de nosotros" (entrevista con Eduardo Quej, Renacimiento Vega Larga 1, agosto de 2017); "mi vecino, quien vive cerca de la casa", "donde pasa la tierra en donde vive”, "donde está lo que está cerca" (entrevista con Mateo Ical, Renacimiento Vega Larga 1, agosto de 2017). Es decir, "lo nuestro" (entrevista con Emiliano Iqui, Washington, junio de 2017), lo que está dentro, alrededor, cerca, y que da circunstancia y posibilidades a la existencia.

Los comunitarios hablaron de "lugares que están en conflicto" o "en proceso" (entrevista con
Juan Saboy, La Ceiba y Dos Fuentes, julio de 2017), así como de "comunidades que están en resistencia" (entrevista con Eduardo Quej, Renacimiento Vega Larga 1, agosto de 2017), con un sentido que superaba la pura imagen geográfica natural. De esta manera, pusieron en evidencia el hecho de que sus circunstancias son de conflicto, que estas comunidades viven en condiciones de amenaza, y en consecuencia, de defensa del territorio, de "nuestro lugar" (entrevista con Abraham Iqui, La Ceiba y Dos Fuentes, junio de 2017, y con José Luis Caal, Renacimiento Vega Larga 1, agosto de 2017).

En los dibujos que realizaron las mujeres durante los talleres participativos sobre el territorio, resalta la identificación, de elementos de la naturaleza, como ríos y montañas, que podrían fungir como manifestaciones territoriales que coexisten en armonía e integran su paisaje. La expresión pictórica concuerda con lo registrado por Rocío García, quien reporta que "para acotar su territorialidad, [los q'eqchi'] recurren frecuentemente a los ríos, no como delimitadores geográficos sino metafóricamente, para explicar cómo nacen de las montañas, recorren los valles hasta fundirse con el mar, es decir se extienden por el tzuultaq'a" (2011: 112). Esta última categoría hace referencia a los guardianes de montes y valles. Los comunitarios de la Sierra de las Minas se expresaron de manera semejante en una reunión intercomunitaria de la resistencia, al referirse a la importancia de las acciones que se realizan en las comunidades localizadas aguas arriba, en la montaña. Comentaron que tales acciones tienen consecuencias para las comunidades ubicadas aguas abajo, en los valles: "lo que pasa en un río nos afecta a todos" (diario de campo, Ribacó, febrero de 2017).

\footnotetext{
5

En Renacimiento Vega Larga 1 y en las otras comunidades en las que se llevó a cabo esta investigación, el maya poqomchi' se ha establecido como el idioma vehicular; por ello, los términos que se analizan en el presente texto corresponden principalmente a esta variante.
} 
Con esta visión de cuenca, los comunitarios constituyen a los ríos en ejes articuladores del territorio, que vinculan y conectan las tierras altas con las medias y bajas en todos los sentidos y aspectos.

Los ríos, concebidos como lugares sagrados, "bienes comunes protegidos por Dios y por los guardianes de las montañas" (entrevista con Eduardo Quej, Renacimiento Vega Larga 1, agosto de 2017), en los que realizan actividades ceremoniales, les ofrecen condiciones de posibilidad para satisfacer sus necesidades alimenticias, de higiene, sociales, recreativas y productivas. En esta comprensión, cualquier lógica o pretensión de apropiación no puede ser aceptada y resulta del todo insensata.

Al preguntar a las personas entrevistadas cuál es su territorio, varias dijeron que es Rex Awaj - piedra verde- - como se conoce a la Sierra de las Minas en maya poqomchi'. Una de las comunitarias afirmó: "para mí, mi territorio es mi familia y mis hijos" (entrevista con Marcela Ichich, La Hamaca, junio de 2017). Un hombre dijo: "el territorio, para mí, es donde vive mi papá (entrevista con Eduardo Quej, Renacimiento Vega Larga 1, agosto de 2017). Otro señaló: "yo creo que el primer lugar es el nosotros, y de ahí, la tierra, los árboles, los animales" (entrevista con José Luis Caal, Renacimiento Vega Larga 1, agosto de 2017).

Es posible afirmar, entonces, que el territorio de las comunidades poqomchi'-q'eqchi' se constituye a partir de relaciones vitales entrelazadas, que sostienen y dan sentido a la existencia colectiva.

Un joven comunitario que transita constantemente entre Renacimiento Vega Larga 1 y la comunidad de origen, Vega Larga, porque su familia es la única que permaneció allí, no pudo definir cuál era su territorio y afirmó no tener uno solo, "porque no tengo un lugar fijo donde esté viviendo" y porque tiene familia en ambos lugares (entrevista con Eduardo Quej, Renacimiento Vega Larga 1, agosto de 2017). Su testimonio habla de la multiterritorialidad que analizara Haesbaert (2013), porque se refiere a experimentar y construir simultáneamente múltiples territorialidades como estrategia de supervivencia en un contexto adverso.

La disposición de las comunidades poqomchi'q'eqchi' para construir multiterritorialidad no debe confundirse con que sean pueblos nómadas, es decir, que migran y se desplazan cíclicamente. Una afirmación semejante ha sido divulgada por los grupos conservacionistas para minimizar los efectos de los desplazamientos forzados. Liza Grandia (2009) y Rocío García (2011) han historizado la dinámica de movilización del pueblo q'eqchi' y han demostrado "que los procesos de desplazamiento han sido provocados [principalmente] por factores como los procesos de concentración de la tierra, el trabajo forzado y la guerra" (García, 2011: 68).

De acuerdo con la propuesta de Haesbaert (2013), en el caso de la comunidad de Renacimiento Vega Larga 1 se destaca su disposición para sobrellevar procesos de desterritorialización y reterritorialización como estrategia de supervivencia frente a la violencia económica; en la búsqueda de mejores condiciones de vida, y también como resistencia frente al despojo y el desplazamiento forzado. Estos procesos, que les han caracterizado por lo menos desde hace un par de generaciones, dan señales de su disposición territorializante, fundamento y consecuencia de sus conocimientos culturales, su cultura ancestral y su posición desfavorable en la correlación de fuerzas del entramado económico vigente.

\section{Ontologías relacionales en las comunidades poqomchi'-q'eqchi'}

Para Escobar (2015: 96), "el territorio se concibe como algo más que una base material para la reproducción de la comunidad humana y sus prácticas. Para poder captar ese algo más, es crucial atender a las diferencias ontológicas". Cuando se habla de diferencias ontológicas, se alude a otros modos de vida - no modernos-, otras concepciones de lo existente y 


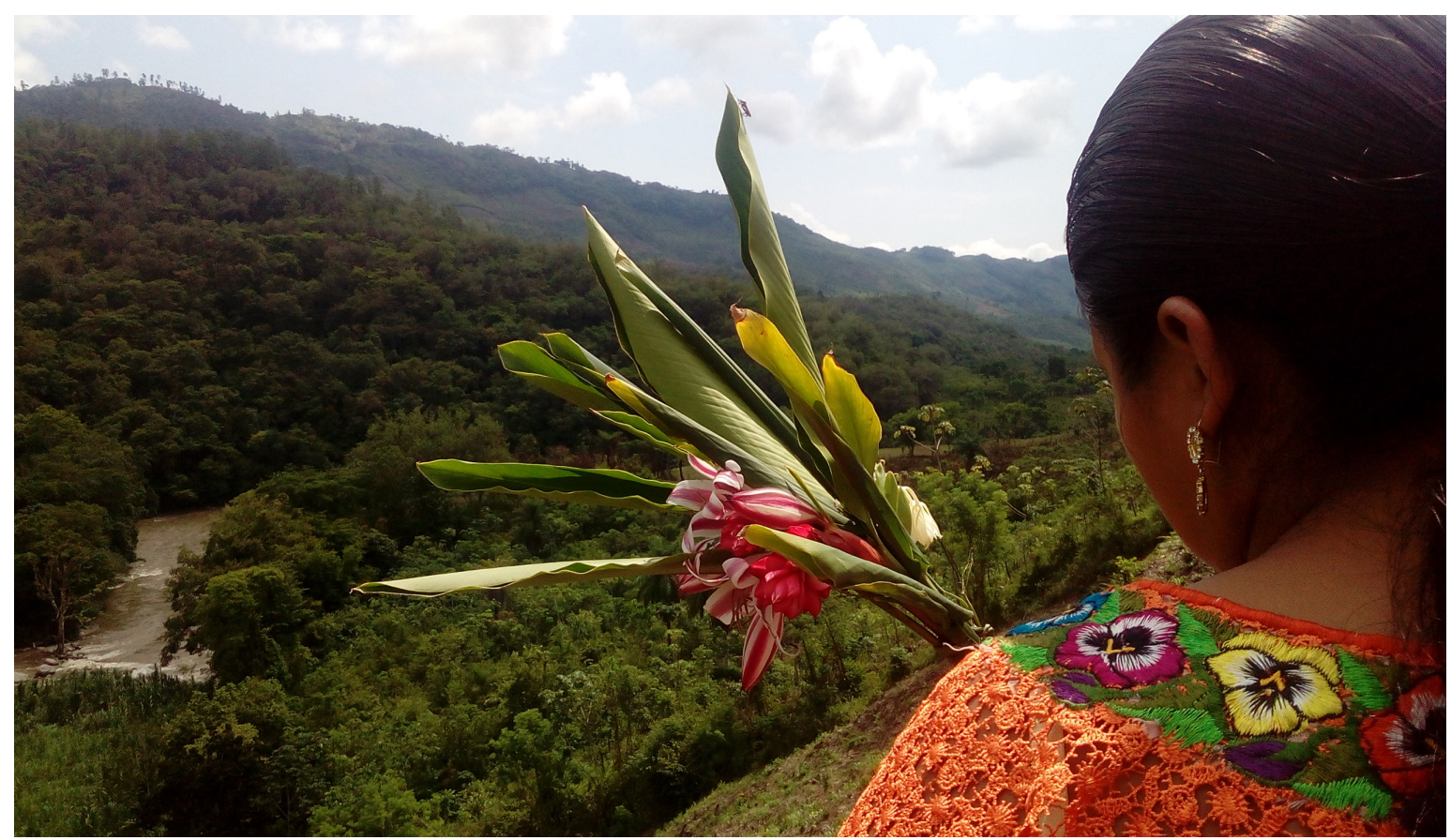

Romina MARTínez VeLARDE • Mujer poqomchi' contempla el río Matanzas. Renacimiento Vega Larga 1.

otras cosmovisiones que afirman la coexistencia al presuponer y asumir las relaciones no subordinadas entre los seres humanos y lo no humano — orgánico, no orgánico, sobrenatural o espiritual — como relaciones intersubjetivas no instrumentales ni utilitaristas.

En estas ontologías, de acuerdo con Escobar $(2015$; 96), los territorios son espacio-tiempos vitales del ser humano y el "mundo natural que circunda y es parte constitutiva de él”. Esto coincide de manera clara con dos de los elementos fundamentales de la noción de sutam de las comunidades poqomchi'-q'eqchi': la referencia a "lo que rodea", "lo cercano", y el entramado de relaciones vitales que esta noción les significa, "lo nuestro", "lo que está dentro".

Una cualidad de los conocimientos culturales de las comunidades poqomchi'-q'eqchi', articulada según su propia constelación de existencia y en relación con su territorio (Limón, 2007), es asignar y reconocer sacralidad al agua, las montañas, bosques y selva, los guardianes de montes y valles, los peñascos y todo lo existente en el sutam, lo que les incita a nutrir estas relaciones con la ejecución de ceremonias en lugares sagrados; relaciones vitales que se entrelazan y forman parte de lo que se incluye en "lo nuestro", la base ontológico-territorial de estas comunidades.

El reconocimiento de los guardianes de montes y valles, yuq' kixk'aab' en poqomchi', y tzuultaq'a en maya q'eqchi', resulta fundamental para aproximarse a la comprensión de la constelación de la existencia de estas comunidades y la dimensión cultural de su defensa del territorio. Si su tenaz lucha no resultara suficiente para detener la embestida extractivista, su vínculo con los guardianes de las montañas vendría a fortalecer su proceso de resistencia. El yuq' kixk'aab'/tzuultaq'a es recuperado por las comunidades en resistencia como símbolo para continuar y animar su lucha en defensa del territorio: "le da 
fuerza a la defensa del territorio las ceremonias que les hacemos a los cerros, así no es tan fácil que nos ataquen porque los cerros nos protegen [...]. Así se levanta el ánimo para seguir la defensa" (entrevista con Arcadio Coy, Renacimiento Vega Larga 1, junio de 2017).

Otro elemento de estas ontologías es los ch'oles, figuras que simbolizan la insubordinación y rebelión de los pueblos indígenas contra los españoles y la religión católica en tiempos de la Colonia, y contra el ejército en tiempos del Conflicto Armado Interno; de ahí que Tezulutlán se autoproclame como región de resistencias. Construida a partir de la existencia de un pueblo real que la habitó, esa región resistió la invasión española y dio muestras de sobrada valentía, mientras que la figura histórico-mitológica de los ch'oles se constituye como símbolo de la oposición a la dominación y referente fundamental en la constelación de la resistencia de las comunidades poqomchi'q'eqchi'. De acuerdo con los testimonios, los ch'oles siguen protegiendo los cerros y montañas, y forman parte de relatos e historias orales que dinamizan la memoria:

Además de los guardianes de las montañas, también hay ch'oles que no quisieron recibir el bautismo y se fueron a vivir a las montañas. Hace tres años, un señor encontró dos cerros, pero le costó entrar, porque había remolinos y se caían árboles, lo hacían para no dejarlo entrar. Dicen que había armas de la guerrilla en esos cerros, que estaban protegidas por los ch'oles (entrevista con Arcadio Coy, Renacimiento Vega Larga 1, junio de 2017).

Así, la comprensión compleja de la naturaleza y sus ciclos remite a la idea de las "ontologías relacionales”, desarrollada por Mario Blaser (2010; 2013), Marisol de la Cadena (2010) y Arturo Escobar (2015). Éstas, que surgen a partir de cuestionar la premisa occidental, racional y moderna de que existe una sola realidad objetiva, crean al mismo tiempo el campo de la ontología política que "toma como punto de partida la existencia de múltiples mundos que, aunque entreverados, no pueden ser completamente reducidos los unos a los otros" (Escobar, 2015: 97). Según el análisis de Jorge Urdapilleta (2016: 17), en la propuesta de los conocimientos culturales se reconoce la diversidad de racionalidades al proclamarse que "la visión de muchos Pueblos nos orienta en sentidos relacionales y más armónicos”. Entonces, el reconocimiento y el respeto a la existencia de mundos múltiples e interrelacionados se busca mediante la confrontación —negación - de lo que históricamente ha negado la existencia de esos otros mundos.

\section{Komonil: existencia colectiva}

En la vida cotidiana de las comunidades mayas poqomchi'-q'eqchi' es muy común escuchar las nociones komoon y komonil. Komoon es la estructura social, política y económica de los pueblos mayas, mientras que el komonil es la acción del komoon. Según el Q'orik Poqomchi': vocabulario poqomchi', de la Academia de Lenguas Mayas de Guatemala (ALMG, 2001: 44), komoon significa “compañero". Esto coincide con gran parte de las respuestas ofrecidas a nuestra pregunta, en las que se contestó que komoon es "un compañero”, pero refiriéndose no sólo a personas humanas sino también a los animales, el agua, etc., aunque hubo quienes señalaron que significa "una persona", "un familiar", "común” y "entre todos". Así que el komoon es la persona cercana, con quien se tiene algo en común.

Komonil, en cambio, según el mismo vocabulario, es "comunidad, grupo" (ALMG, 2001: 44). De acuerdo con los testimonios, dos palabras se traducen como "comunidad", una es ab'iixb'al, que refiere al lugar o espacio físico que ocupa un núcleo poblacional, y la otra es komonil, que alude al sentido colectivo, de unidad; de manera que cuando se dice: "xojkamanik pan komonil”, significa "trabajamos en grupo". 
En cuanto a cómo debe ser entendida la palabra komonil, identificamos tres dimensiones interrelacionadas: a) una acorde a su significado asambleario, estar juntos, en grupo, reunidos para tomar decisiones en conjunto; b) otra que refiere a lo común y colectivo, de todos, y c) pan komonil, la potencia de la unión, el nosotras/nosotros colectivo, caminando en unidad y de manera autónoma.

Ésta fue una de las respuestas, que resulta elocuente e integradora:

Komonil para mí es toda la gente que participa en una asamblea. Es donde llega toda la gente y da voz de lo que hay que hacer en una comunidad, en una región, en una zona. Es el komonil, como decimos nosotros, el que manda, quien decide qué es lo que conviene, lo que está a favor de nosotros. Ése es el komonil, donde vienen y participan todos. Es la fuerza más grande (entrevista con Eduardo Quej, Renacimiento Vega Larga 1, agosto de 2017).

En esta definición se enfatiza el proceso asambleario: quiénes lo constituyen, cuáles son sus funciones y responsabilidades, cuál es la importancia. Así, es posible señalar que la asamblea es el motor de la participación y organización comunitaria: "es donde llega toda la gente y da voz”. Ahí también se definen las prioridades comunitarias: "la gente da voz de lo que hay que hacer en una comunidad". Incluso es el proceso de diálogo y deliberación para lograr acuerdos sociales: "es el komonil quien decide qué es lo que conviene" (entrevista con Eduardo Quej, Renacimiento Vega Larga 1, agosto de 2017).

Cuando Eduardo Quej afirma en su testimonio que el komonil es "la fuerza más grande", habla de la asamblea como elemento central en la vida de las comunidades poqomchi'-q'eqchi' y manifestación de su forma privilegiada de organizarse y decidir.

El sello de goma que utiliza la comunidad de Renacimiento Vega Larga 1 para formalizar sus actas lleva inscrita la leyenda: "maya poqomchi' rak'un ak'al q'eqchi' ralch'och", que significa "hijos e hijas de la tierra maya poqomchi'-q'eqchi"'. Resulta significativa su reivindicación como "hijos e hijas de la tierra". Para estar en komonil se requiere que estén, participen y den su voz tanto los hijos como las hijas de la tierra. Así lo confirmó un comunitario: "si las mujeres no participan, no estamos en komonil" (entrevista con Arcadio Coy, Renacimiento Vega Larga 1, junio de 2017). Su expresión es contundente y deja en claro que la voz y participación de las mujeres es absolutamente fundamental, de no estar ellas y no participar, no se está en komonil.

Un testimonio que articula komonil y sutam es el siguiente: "hay lugares que son de toda la comunidad, del komonil, como las riberas de los ríos y los lugares sagrados. Hay personas específicas, designadas en komonil, encargadas de cuidar esos lugares" (entrevista con Arcadio Coy, Renacimiento Vega Larga 1, junio de 2017).

Este testimonio incluye al menos dos elementos relevantes: la identificación en el sutam de lugares colectivos, comunes a toda la comunidad, como las riberas de los ríos y los lugares sagrados, y la labor de las personas encargadas de cuidar estos lugares, designadas por la asamblea comunitaria, por lo cual su labor no sólo se debe a la fuerza de su disposición personal. Así, la noción de komonil no es una cuestión abstracta o solamente teórica, sino que se sostiene en prácticas y decisiones cotidianas de la vida comunitaria, que también dan sustento al sutam.

Otro testimonio que nos ayuda a entender la constelación del komonil es el siguiente: "komonil significa para mí que todos nos agarramos, que todos caminamos juntos, que nadie ya nos va a mandar, sino que nos vamos a mandar solos, nos vamos a cuidar sólo nosotros" (entrevista con Rigoberto Juc, Renacimiento Vega Larga 1, julio de 2017).

Con estas palabras, Rigoberto Juc expone una noción esperanzada del komonil y un rechazo al mandato de otras personas. Debe recordarse que las experiencias de su trabajo como mozos en las fincas 


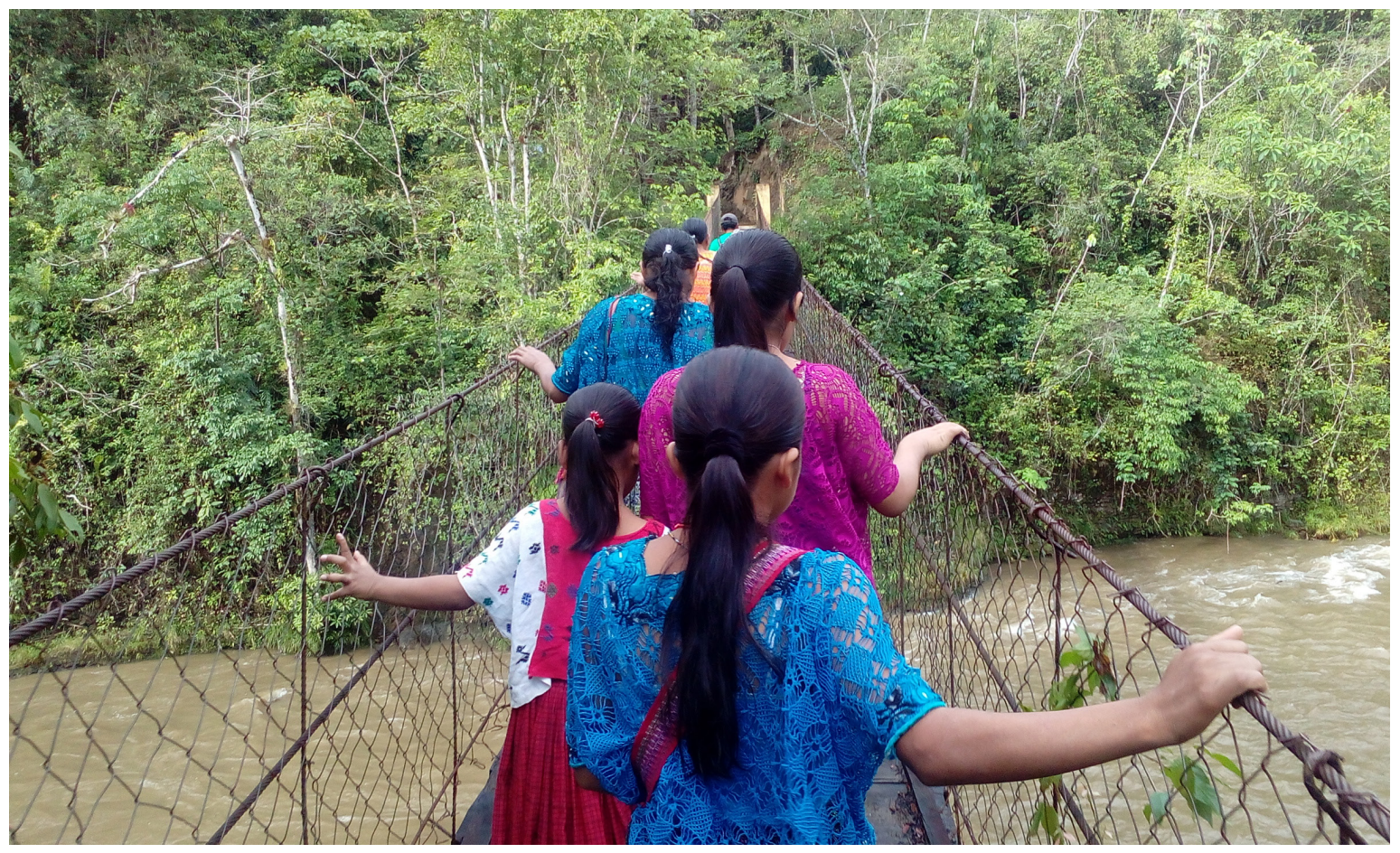

Romina MARTínez VelaRde Mujeres poqomchi' atraviesan el río Matanzas. Renacimiento Vega Larga 1.

—condición en la que aún viven muchas familias en la región-corresponden al mandato legal que les arrebató sus tierras y los desplazó a otro sitio. Si bien este testimonio remarca el sentido colectivo y de unidad, aporta un elemento central en su condición de vida y sentido colectivo, que es significativo, y por lo tanto, cultural: la autonomía - "nos vamos a mandar solos"; "nos vamos a cuidar sólo nosotros"-

A este respecto, cuando se preguntó en uno de los talleres participativos cómo se podría traducir la noción de autonomía en idioma maya poqomchi', los comunitarios dijeron que como 'rub'ehik qiib' chiqib'il", cuya traducción literal es "ir caminando/ empezar el camino entre nosotros". Esto corresponde plenamente al principio de esperanza que Ernst Bloch (1980) trabajó con toda profundidad. Este "ir caminando" o "empezar el camino" conlleva, además, un sentido y una lógica de proceso; no se trata de una aspiración que se logra de un día para otro, sino de un posicionamiento y una búsqueda, una construcción que casi siempre es lenta, o por lo menos paulatina, pero que tiene noción de profundidad.

A partir de lo anterior y lo observado e intercambiado durante el trabajo de campo, es posible señalar que el komonil, lo comunitario - el hecho de reunirse, encontrarse, estar e ir en unidad-, es un elemento central y articulador del modo de vida poqomchi'-q'eqchi', de su forma de ser y situarse en el mundo. Por ello no puede entenderse de manera aislada del sutam, pues es el modo cultural de entender todo, de entender el entorno y asumir la relación con él.

\section{Anhelos comunitarios como proyección de vida}

Los conocimientos culturales, como forma de comprensión de la vida, se proyectan a sí mismos en el territorio como memoria y esperanza. Por lo tanto, 
el reconocimiento del carácter cultural de los conocimientos es coherente con los procesos de resistencia de los pueblos y comunidades que defienden su territorio, y se encuentra en sintonía con sus luchas y anhelos colectivos. Estos esfuerzos son históricos y de largo aliento, y están vigorizados por los recuerdos, tanto de los dolores y fracasos como de las conquistas y la resistencia, con los que se hace frente a la desmemoria y el olvido inducidos por el poder y sus pretensiones modernistas y desarrollistas.

Para Echeverría (2010: 40), cuando se observa a una comunidad "tal como es cuando se empeña en llevar a cabo su vida persiguiendo un conjunto de metas colectivas que la identifican", aparece lo cultural, como dimensión de la existencia social, con todos sus aspectos y funciones.

En uno de los talleres, en el que participó un grupo de mujeres y hombres de Renacimiento Vega Larga 1, se abordó el tema de los anhelos comunitarios. Algunos de los testimonios que se compartieron, comunes a hombres y mujeres, son los siguientes:

"Que no haya nadie que nos mueva. Encontrar el equilibrio. Que seamos siempre fuertes y que nadie nos esté molestando. Que crezca la comunidad y que sigamos juntos para delante".

"Nosotros ya no nos vamos a dejar engañar; el fruto es ya no dejarnos engañar. Ya no nos vamos a dejar engañar; los ricos no nos van a joder".

"Que nos levantemos en comunidad para que tengamos fuerza y tengamos vida. Lo bonito va a ser cuando veamos que todos juntos nos estamos levantando y cuando podamos decir que todos juntos nos estamos levantando".

“Tenemos que buscar la forma de cómo a nuestros hijos les vamos a fortalecer sus ideas y sus pensamientos. Uno de los frutos que queremos es que los niños se levanten y se organicen. Queremos que los niños y niñas sepan sobre resistencia, y que sepan su historia. Tenemos que darles consejos a nuestros hijos y a nuestras hijas" (taller sobre anhelos comunitarios con mujeres y con hombres, Renacimiento Vega Larga 1, agosto de 2017).

Conscientes de las amenazas que pesan sobre su territorio, se pronuncian en el sentido de que "no quieren más engaños", y no desean que "los sigan molestando" ni que "los ricos los jodan". Frente a esas amenazas, se convencen de defender su modo de vida propio como antagónico al sistema dominante y vigorizar sus conocimientos culturales. Se asumen como una comunidad en resistencia, en defensa de su territorio, y comprenden el riesgo de que intenten dividirlos, sacarlos de equilibrio y debilitar su organización. Para no sucumbir, defienden y fortalecen lo propio ante lo ajeno.

La potente alusión a "levantarse todos para que tengamos fuerza y tengamos vida" puede interpretarse como negatividad: poner un alto, decir no al aniquilamiento, ponerse de pie. Invita a la dignidad, a no dejarse doblegar. También lleva implícita una dimensión ontológica pura del sentido de la vida y una propuesta contra el olvido, mediante el recurso de la memoria.

Tampoco quieren que sus ríos se dividan. De acuerdo con los testimonios recabados, una de sus principales demandas frente a los proyectos hidroeléctricos es clara: “iqueremos que todos los ríos del municipio de Purulhá, en Sierra de las Minas, Guatemala, sean libres!” (diario de campo, Ribacó, febrero de 2017). Es decir, quieren que los ríos fluyan con libertad, sin cortinas de concreto ni tubos que modifiquen su camino ni alteren su caudal natural.

Por otra parte, el énfasis en que las niñas y los niños de la comunidad “se organicen”, "se levanten", "sepan sobre resistencia" y "sepan su historia" es una invitación al conocimiento y la comprensión 
de la dimensión histórica. Se trata del recuerdo vivo dentro de la memoria.

Otro aspecto que debe remarcarse es la construcción de su proceso de autonomía, uno de los anhelos comunitarios más profundos, más enfatizados y sentidos. Para ahondar en esta cuestión, cuando se les preguntó qué entendían por autonomía, contestaron, entre otras cosas, lo siguiente: "mirarnos entre nosotros mismos" (entrevista con Marcela Ichich, La Hamaca, junio de 2017); "estar libre del mando del gobierno" (entrevista con Eduardo Quej, Renacimiento Vega Larga 1, agosto de 2017); “tener nuestro propio gobierno" (entrevista con Gerardo Chub', Renacimiento Vega Larga 1, agosto de 2017); “que la comunidad tenga su propia idea para administrar su territorio" (entrevista con Mateo Ical, Renacimiento Vega Larga 1, agosto de 2017); “"hacer nuestros propios proyectos y no recibir proyectos del gobierno" (entrevista con José Luis Caal, Renacimiento Vega Larga 1, agosto de 2017); “caminar de buena forma", "vivir juntos, en tranquilidad y en paz" (entrevista con Eduardo Quej, Renacimiento Vega Larga 1, agosto de 2017); "hacer reuniones para resolver nuestros propios problemas" (entrevista con Abraham Iqui, La Ceiba y Dos Fuentes, junio de 2017); "que no vengan otras personas a decirnos qué hacer", "tener nuestro propio curandero, comadrona, médico" (entrevista con Gerardo Chub', Renacimiento Vega Larga 1, agosto de 2017); “que en nuestras manos quede lo que le conviene a la comunidad" (entrevista con Emiliano Iqui, Washington, junio de 2017); "nosotros mismos guiar nuestro destino" (taller sobre línea del tiempo a futuro con mujeres, Renacimiento Vega Larga 1, agosto de 2017).

Para la gente de esta comunidad, la autonomía no es sólo una noción teórica o abstracta, sino que está aterrizada en la práctica y el quehacer cotidiano, lo que la dota de contenido y sentido. La búsqueda de autonomía constituye un principio ético básico y un posicionamiento político, pues establece normas claras frente a actores externos como el gobierno, los ricos y los empresarios, y es también faro que ilumina el horizonte utópico hacia el cual quieren "caminar de buena forma".

Si bien los miembros de la comunidad de Renacimiento Vega Larga 1 tienen la claridad de que la construcción de su autonomía es un proceso largo, saben que ya han comenzado a dar pasos en ese sentido. De acuerdo con John Holloway (2015), la esperanza se encuentra en estos procesos - grietas del sistema hegemónico- - y en su expansión, multiplicación y confluencia.

Entre los elementos de autonomía que la gente identifica como sus conquistas están: decir no a quienes han intentado negarlos y a los proyectos que han tratado de imponerles en sus territorios - negar la negación es un factor fundamental de la autonomía-; la decisión de ya no tener Consejos Comunitarios de Desarrollo Urbano y Rural oficiales sino autoridades indígenas autónomas; el uso y la defensa de la medicina tradicional y la ruptura de relaciones con organizaciones no gubernamentales internacionales que no aportan al proceso comunitario.

Respecto de la medicina indígena, se afirma lo siguiente:

Nuestros padres y abuelos, algunos de ellos ahora
están vivos y son curanderos o hierberos. Ellos nos
han enseñado a curarnos con hierbas [...]. Ahora,
digamos que no queremos la salud que viene de
fuera, porque tenemos nuestra propia salud, pero
sin curanderos y sin hierberos no podemos vivir en
autonomía. Por eso, ellos nos dan fuerza también
(entrevista con Gerardo Chub', Renacimiento Ve-
ga Larga 1, agosto de 2017).

Mantener, defender y renovar sus conocimientos culturales —idiomas, ceremonias, prácticas agrícolas, medicina tradicional, forma de vestir, forma de convocarse, entre otros- y ponerlos en práctica para sostener y fortalecer su lucha es también un 
elemento fundamental para la construcción de su proceso autonómico.

\section{Reflexiones finales}

La comunidad de Renacimiento Vega Larga 1 vive el día a día con un sentido de resistencia y organización al actualizar constantemente una larga tradición de lucha frente al despojo y el embate de los proyectos extractivistas.

Los proyectos hidroeléctricos, de minería e industria maderera que se tratan de imponer en el territorio de la Sierra de las Minas — con mayor intensidad a partir de 1996, después de la firma de los Acuerdos Paz - han hecho que "ahora se tenga que luchar más” (entrevista con Eduardo Quej, Renacimiento Vega Larga 1, agosto de 2017). Estos proyectos no son aislados, pues la gente refiere que la posesión de sus tierras siempre ha estado asociada a la lucha por su defensa. Aunque la categoría de defensa del territorio es relativamente reciente, ésta alude a tradiciones comunitarias de lucha y formas culturales muy antiguas.

El sutam de las comunidades poqomchi'-q'eqchi', comprendido como un lugar amplio que sostiene a la comunidad, está a su alrededor y se asume como responsabilidad propia, es un espacio que, si bien está en disputa, no es negociable. Ahí vive la comunidad y por ello se le defiende. En el sutam se vive la vida con todo su entramado de relaciones, con absolutamente todo cuanto allí coexiste: ríos, montañas, animales, plantas y guardianes de montes y valles, con quienes se tiene una relación de codependencia.

Los procesos de desterritorialización, por el desplazamiento de la comunidad de Vega Larga, y reterritorialización, en Renacimiento Vega Larga 1 , constituyen un cúmulo de vivencias y sentimientos ligados a este nuevo espacio. Así, identificamos una multiterritorialidad experimentada por el ir y venir de un espacio a otro y por la dinámica de organización entre todas las comunidades en resistencia en la Sierra de las Minas, que permite mantener una territorialidad en red.

El komonil, con sus tres dimensiones interrelacionadas, la asamblearia, la de la posesión en común y la de la unión como potencia para caminar hacia la autonomía, es un elemento central y articulador del modo de vida poqomchi'-q'eqchi', de su forma de ser y situarse en el mundo, en su sutam. Se vive en comunidad para dialogar, discutir y enfrentar en unidad los problemas; para ayudarse y cuidarse recíprocamente; para mantenerse unidos. Ésa es una fuerza para su vida, pero también para su lucha; es su raíz.

Si bien el principio del komonil está centrado en las personas, esta noción incluye otras formas de vida no humana, como animales, plantas, ríos, cerros, cielo y guardianes de montes y valles. Una clara comprensión de las múltiples relaciones que se presentan en la naturaleza vuelve improcedente cualquier lógica o intento de apropiación, por su insensatez.

En nuestro trabajo de campo constatamos que los conocimientos culturales de las comunidades poqomchi'-q'eqchi', su forma de comprensión de la vida, el entorno y el territorio, se basan en su memoria y están llenos de esperanza. Son parte medular y sustento de la lucha y la defensa de sus territorios y modos de vida. La esperanza que se yergue desde aquí se configura como su sueño colectivo y trasciende las generaciones actuales. Estos conocimientos son los que orientan sus anhelos de libertad y autonomía.

La dimensión cultural mantiene y aviva la defensa del territorio de las comunidades poqomchi'q'eqchi' de la Sierra de las Minas porque confiere un sentido de trascendencia a su caminar y lo articula con todo el entramado de elementos significativos de su cultura. En esta lógica, su komonil encuentra sentido y potencia en la lucha y organización de la defensa del sutam. D 


\section{Bibliografía}

Academia de Lenguas Mayas de Guatemala (ALMG), 2001, Q'orik Poqomchi': vocabulario poqomchi', Academia de Lenguas Mayas de Guatemala/Dirección Lingüística y Cultural/Programas de Estudios Lingüísticos, Guatemala.

Bezos, Javier, 2012, “Uso de las minúsculas en español”, en Fundéu BBva, asesorado por la Real Academia Española. Disponible en línea: <https://www.fundeu.es/noticia/uso-de-las-minusculas-en-espanol-2-de-4-7247/>. Consultado el 28 de enero de 2018.

Blaser, Mario, 2010, Storytelling Globalization from the Chaco and Beyond, Duke University Press, Durham.

- 2013, "Ontological Conflicts and the Stories of People in Spite of Europe: Towards a Conversation on Political Ontology", en Current Anthropology, vol. 54, núm. 5, pp. 547-568.

Bloch, Ernst, 1980 [1954], El principio esperanza, tomos I, II y III, Aguilar, Madrid.

Cadena, Marisol de la, 2010, "Indigenous Cosmopolitics in the Andes: Conceptual Reflections beyond Politics", en Cultural Anthropology, vol. 25, núm. 2, pp. 334-370.

Echeverría, Bolívar, 2010, Definición de la cultura, Fondo de Cultura Económica, México.

Escobar, Arturo, 1999, “Comunidades negras de Colombia: en defensa de biodiversidad, territorio y cultura”, en Biodiversidad, núm. 22, pp. 15-20.

—_, 2014, Sentipensar con la tierra. Nuevas lecturas sobre desarrollo, territorio y diferencia, Fondo Editorial de la Universidad Autónoma Latinoamericana (Pensamiento Vivo), Medellín.

__ , 2015, “Territorios de diferencia: la ontología política de los 'derechos al territorio'”, en Desenvolvimento e meio ambiente, vol. 35, pp. 89-100.

García, Rocío, 2011, Territorio kaxlan-territorio q'eqchi'. Conflictos en áreas protegidas de Livingston, Izabal, tesis de licenciatura en antropología, Universidad de San Carlos de Guatemala-Escuela de Historia-Área de Antropología, Guatemala.

— 2013 , "Un ¿nuevo? modelo de áreas protegidas que concilia las industrias extractivas con la conservación de la naturaleza y el desarrollo rural", en El Observador. Industrias extractivas: despojo y destrucción, año 8, núms. 40-41, pp.18-21.

Grandia, Liza, 2009, Tz'aptz'ooqeb'. El despojo recurrente al pueblo q'eqchi', Asociación para el Avance de las Ciencias Sociales en Guatemala, (Autores invitados, 20), Guatemala.

Giménez, Gilberto, 2005, "Territorio e identidad. Breve introducción a la geografía cultural”, en Trayectorias, vol. VII, núm. 17, pp. 8-24.

Hadad, Gisela y César Gómez, 2007, "Territorio e identidad. Reflexiones sobre la construcción de territorialidad en los movimientos sociales latinoamericanos", en Actas de las IV Jornadas de Jóvenes Investigadores, Instituto de Investigaciones Gino Germani-Facultad de Ciencias Sociales-Universidad de Buenos Aires, 19, 20 y 21 de septiembre, Buenos Aires.

Haesbaert, Rogério, 2013, "Del mito de la desterritorialización a la multiterritorialidad”, en Cultura y Representaciones Sociales, año 8, núm. 15, pp. 9-42.

Hoetmer, Raphael, 2017, “Esta democracia ya no es democracia. Siete hipótesis exploratorias sobre biopolítica extractivista, la criminalización de la disidencia, y alternativas", en Colectivo Tejiendo Saberes - Programa de Estudios sobre Democracia y Transformación Global (PDTG), 25 de agosto de 2017. Disponible en línea: <https://democraciaglobal.org/raphael-hoetmer-esta-democracia-ya-no-democracia-sietehipotesis-exploratorias-biopolitica-extractivista-la-criminalizacion-la-disidencia-alternativas>.

Holloway, John, 2015, "Pensar la esperanza, pensar la crisis", en Rafael Sandoval (ed.), Pensar desde la resistencia anticapitalista y la autonomía, Cátedra Jorge Alonso-Centro de Investigaciones y Estudios Superiores en Antropología Social, Guadalajara, pp. 87-97.

Limón, Fernando, 2007, Memoria y esperanza en el pueblo maya chuj. Conocimiento cultural y diálogos en frontera, tesis de doctorado en sociología, Benemérita Universidad Autónoma de Puebla-Instituto de Ciencias Sociales y Humanidades "Alfonso Vélez Pliego", Puebla. , 2008, "La ciudadanía del pueblo chuj en México, una dialéctica negativa de identidades", en Alteridades, núm. 18, pp. 85-98. 2009, Historia chuj a contrapelo. Huellas de un pueblo con memoria, El Colegio de la Frontera Sur/Consejo de Ciencia y Tecnología del Estado de Chiapas, San Cristóbal de Las Casas.

__ 2010, Conocimiento cultural y existencia entre los chuj, Comisión Nacional para el Desarrollo de los Pueblos Indígenas (Antropología Social, 101), México.

López, Mario Estuardo, 2016, Comunidades que luchan. Negatividad y resistencia en Ribacó (Purulhá, Baja Verapaz, 1990-2014), tesis de doctorado en sociología, Benemérita Universidad Autónoma de Puebla-Instituto de Ciencias Sociales y Humanidades "Alfonso Vélez Pliego", Puebla. 
Martínez, Jorge, 2006, El pueblo q'eqchi: entre un pasado difícil y un futuro esperanzador, Servicios Ecuménicos de Formación en Centroamérica, Guatemala.

Martínez-Alier, Joan, 2015, “Ecología política del extractivismo y justicia socioambiental”, en Interdisciplina, vol. 3, núm. 7, pp. 57-73.

Navarro Mina, Lorena, 2013, "Las luchas indígenas y campesinas contra el despojo capitalista en México: subjetividades políticas en la defensa y gestión de los bienes comunes naturales", en Boletín Onteaiken, núm. 15, pp. 71-84.

Porto-Gonçalves, Carlos Walter, 2002, "Da Geografia às geografias. Um mundo em busca de novas territorialidades”, en Ana Esther Ceceña y Emir Sader (comps.), La guerra infinita: hegemonía y terror mundial, Consejo Latinoamericano de Ciencias Sociales, Buenos Aires, pp. 217-256.

Primera Declaración de Tezulutlán, 2012, Primer Encuentro de Tezulutlán, 9 de agosto.

Real Academia Española (RAE), 2005, Diccionario panhispánico de dudas. Disponible en línea: <http://buscon.rae.es/dpd/srv/search?id= BapzSnotjD6nOvZiTp>. Consultado el 28 de enero de 2018.

Universidad Rafael Landívar (URL), 1992, Escribiendo q'eqchi', 2a. edición, Instituto de Lingüística, Guatemala.

Urdapilleta, Jorge, 2016, "Conocimientos culturales: mirando los modos particulares de vivir de los pueblos", en Minerva Yoimy Castañeda y María Gabriela López Suárez (coords.), Comunicación intercultural: a diez años de la Universidad Intercultural de Chiapas, Universidad Intercultural de Chiapas, San Cristóbal de las Casas, pp. 39-64.

Vela-Peón, Fortino, 2001, “Un acto metodológico básico de la investigación social: la entrevista cualitativa”, en Maria Luisa Torrés (comp.), Observar, escuchar y comprender. Sobre la tradición cualitativa en la investigación social, Porrúa/Facultad Latinoamericana de Ciencias Sociales, México, pp. 63-95.

\section{Entrevistas}

Abraham lqui, 48 años de edad, La Ceiba y Dos Fuentes, junio de 2017. Arcadio Coy, 54 años de edad, Renacimiento Vega Larga 1, junio de 2017. Eduardo Quej, 31 años de edad, Renacimiento Vega Larga 1, agosto de 2017. Emiliano Iqui, 40 años de edad, Washington, junio de 2017.

Gerardo Chub', 25 años de edad, Renacimiento Vega Larga 1, agosto de 2017. José Luis Caal, 37 años de edad, Renacimiento Vega Larga 1, agosto de 2017. Juan Saboy, 56 años de edad, La Ceiba y Dos Fuentes, julio de 2017. Marcela Ichich, 28 años de edad, La Hamaca, junio de 2017. Mateo Ical, 57 años de edad, Renacimiento Vega Larga 1, agosto de 2017 Rigoberto Juc, 57 años de edad, Renacimiento Vega Larga 1, julio de 2017. 